\title{
Delta Sleep Response to Metyrapone in Post-Traumatic Stress Disorder
}

\author{
Thomas C Neylan*, 1,2, Maryanne Lenoci, ${ }^{1,2}$, Melissa L Maglione ${ }^{1,2}$, Nicholas Z Rosenlicht ${ }^{1,2}$, Thomas J \\ Metzler $^{1,2}$, Christian Otte ${ }^{1,2}$, Frank B Schoenfeld ${ }^{1,2}$, Rachel Yehuda ${ }^{3}$ and Charles R Marmar',2 \\ 'Department of Psychiatry, University of California, USA; ${ }^{2}$ Psychiatry Service, San Francisco Veterans Affairs Medical Center, San Francisco, CA, \\ USA; ${ }^{3}$ Department of Psychiatry at the Mount Sinai School of Medicine, USA
}

\begin{abstract}
Metyrapone blocks cortisol synthesis, which results in the stimulation of hypothalamic cortiocotropin-releasing factor (CRF) and a reduction in delta sleep. We examined the effect of metyrapone administration on endocrine and sleep measures in male subjects with and without chronic PTSD. We hypothesized that metyrapone would result in a decrease in delta sleep and that the magnitude of this decrease would be correlated with the endocrine response. Finally, we utilized the delta sleep response to metyrapone as an indirect measure of hypothalamic CRF activity and hypothesized that PTSD subjects would have decreased delta sleep at baseline and a greater decrease in delta sleep induced by metyrapone. Three nights of polysomnography were obtained in 24 male subjects with combatrelated PTSD and 18 male combat-exposed normal controls. On day 3, metyrapone was administered during normal waking hours until habitual sleep onset preceding night 3. Endocrine responses to metyrapone were measured in plasma obtained the morning following sleep recordings, the day before and after administration. Repeated measures ANOVAs were conducted to compare the endocrine and sleep response to metyrapone in PTSD and controls. PTSD subjects had significantly less delta sleep as indexed by stages 3 and 4, and total delta integrated amplitude prior to metyrapone administration. There were no differences in premetyrapone cortisol or ACTH levels in PTSD vs controls. PTSD subjects had a significantly decreased ACTH response to metyrapone compared to controls. Metyrapone caused an increase in awakenings and a marked decrease in quantitative measures of delta sleep that was significantly greater in controls compared to PTSD. The decline in delta sleep was significantly associated with the magnitude of increase in both IIdeoxycortisol and ACTH. The results suggest that the delta sleep response to metyrapone is a measure of the brain response to increases in hypothalamic CRF. These data also suggest that the ACTH and sleep EEG response to hypothalamic CRF is decreased in PTSD.

Neuropsychopharmacology (2003) 28, I666-1676, advance online publication, I I June 2003; doi: I0.1038/sj.npp. I 3002 I 5
\end{abstract}

Keywords: PTSD; sleep; metyrapone; ACTH; corticotropin-releasing factor

\section{INTRODUCTION}

Multiple studies have demonstrated that PTSD patients complain of recurrent nightmares and sleep continuity disturbances, which are listed separately in the re-experiencing and hyperarousal clusters in the DSM-IV criteria. Roszell et al (1991) found in a study of 116 Vietnam veterans receiving treatment in a PTSD specialty clinic that disturbed sleep, separate from nightmares, was the most frequently reported symptom ( $90 \%$ of subjects). Hyperarousal during sleep, a well-established finding in mood and

*Correspondence: Dr TC Neylan, PTSD Program, Psychiatry Service II6P, Veterans Affairs Medical Center, 4I50 Clement Street, San Francisco, CA 94121, USA. Tel: + I 415750 6961, Fax: + | 415751 2297, E-mail: neylan@itsa.ucsf.edu

Received 08 October 2002; revised 03 February 2003; accepted 03 April 2003

Online publication: 22 April 2003 at http://www.acnp.org/citations/ Npp0422373/default.pdf psychotic disorders, is demonstrable on polysomnography by increased awakenings and decreased sleep depth as measured by the levels of slow wave or delta sleep. In healthy subjects, delta sleep activity is maximal in the first half of the night and is temporally associated with peak growth hormone release and the nadir of cortisol output (Van Cauter et al, 2000). Many studies in subjects with major depression have documented reduced delta sleep, increased cortisol release, and reduced growth hormone output as reviewed by Riemann et al (2001). These studies along with an extensive literature in healthy subjects support the hypothesis that delta sleep is in part mediated by hormonal factors and is associated with the homeostatic and physical restorative function of sleep (Borbely and Achermann, 2000; Feinberg, 1974; Vgontzas et al, 1999). Hence it is surprising that only two studies have shown that PTSD, a putative hyperarousal disorder, is associated with decreased visually scored delta sleep (Glaubman et al, 1990; Kramer and Kinney, 1988). This contrasts with a larger 
number of studies of PTSD that have found no differences in visually scored delta sleep (Brown and Boudewyns, 1996; Dagan et al, 1991; Dow et al, 1996; Hefez et al, 1987; Hurwitz et al, 1998; Klein et al, 2002; Lavie et al, 1979; Mellman et al, 1995a, b, c, 1997; Ross et al, 1994a, b; Woodward et al, $1996 a, b, c)$. This might suggest that individuals with PTSD misperceive their sleep duration and depth, or that mediators of delta sleep, such as nocturnal hormone activity, differ in PTSD compared to other hyperarousal disorders such as depression.

Another possible explanation for failing to find reduced delta sleep in PTSD relates to the poor sensitivity of visual sleep staging, or sleep macroarchitecture, in quantifying delta sleep (reviewed in Uchida et al, 1999). Visual scoring is based on arbitrary criteria that produce a crude single category score (eg stage 4) for each epoch of sleep, which obscures the complexity of the sleep electroencephalogram (EEG). Further, visually scored delta sleep typically represents a small fraction of total sleep time and most studies lack the power to detect significant group differences. Woodward and colleagues have published the only study that employed quantitative analysis of the sleep EEG in PTSD subjects. In this study, the distinguishing feature in a sample of 56 unmedicated Vietnam combat veterans was that subjects with PTSD compared to controls had significantly decreased delta spectral power during nonrapid-eye-movement (NREM) sleep (Woodward et al, 2000). For this reason, studies utilizing quantitative measures of the sleep EEG may be more informative in studies of PTSD. Further, challenge paradigms that manipulate delta sleep, such as sleep deprivation or administration of certain drugs, may be needed in order to better characterize delta sleep regulation in PTSD.

A large body of literature suggests that elevations in both hypothalamic (neurohormonal) and extrahypothalamic (neurotransmitter) corticotropin-releasing factor (CRF) release is associated with decreased delta sleep activity. The evidence supporting the role of increased extrahypothalamic CRF being associated with decreased delta sleep includes studies in which intracerebroventricular administration of CRF in adult rats results in a potent reduction in delta sleep (Ehlers et al, 1986; Chang and Opp, 2001). Further, intracerebroventricular blockade of central CRF receptors in freely behaving rats reduces spontaneous waking (Chang and Opp, 1998). The evidence supporting the role of increased hypothalamic CRF being associated with decreased delta sleep includes the following: (1) Hypercortisolemic depression is associated with increased hypothalamic CRF and decreased delta sleep (reviewed in (Gold et al, 1988a, b)). (2) There is a strong inverse relation between delta sleep and pulsatile cortisol release (see Vgontzas et al, 1999; Born et al, 1991 for a review). The apparent relation between peripheral cortisol levels and delta sleep is likely to be driven by the activity of hypothalamic CRF, because exogenous cortisol infusion, which reduces CRF in the paraventricular nucleus (PVN), increases delta sleep (Friess et al, 1994; Bohlhalter et al, 1997). (3) Metyrapone administration, which leads to an increase in hypothalamic, but not extrahypothalamic CRF (Kalin et al, 1987), causes a decrease in delta sleep (Jahn et al, 1996).
Metyrapone administration is used diagnostically to test the integrity of the entire HPA axis. It blocks the enzymatic conversion of 11-deoxycortisol to cortisol resulting in a stimulation of hypothalamic CRF and ACTH and subsequent accumulation of 11-deoxycortisol (Fiad et al, 1994). Metyrapone acutely reduces cortisol levels and eliminates cortisol-mediated feedback inhibition of the HPA axis. Metyrapone effectively exposes the underlying drive of the PVN to release CRF and arginine vasopressin (Akil and Morano, 1995). Metyrapone administration in rats resulted in EEG activation and reduced sleep time. In this study, the metyrapone effect on sleep was mediated by the rise of hypothalamic CRF as opposed to the drop in cortisol (Burade et al, 1996). EEG activation and loss of sleep time was reversed by anti-CRF antibodies.

PTSD may be associated with increases in both extrahypothalamic and hypothalamic CRF activity. Two studies have found higher levels of CRF in cerebrospinal fluid (CSF) in PTSD (Baker et al, 1999; Bremner et al, 1997). CSF reflects mainly extrahypothalamic sources (Kalin et al, 1987; Vythilingam et al, 2000). Increased hypothalamic CRF in PTSD is thought to explain, in part, the blunted ACTH response to CRF in PTSD found in some (Heim et al, 2001; Smith et al, 1989) but not all studies (Kellner et al, 2002; Rasmusson et al, 2001). Increased hypothalamic CRF has also been inferred from a number of studies that have found elevated cortisol levels in PTSD (De Bellis et al, 1999; Lemieux and Coe, 1995; Liberzon et al, 1999; Maes et al, 1998; Pitman and Orr, 1990). Despite possible elevated hypothalamic CRF activity, PTSD subjects in a large number of studies have been found to have either normal (Baker et al, 1999) or decreased 24-h urinary cortisol (Mason et al, 1986; Yehuda et al, 1995; Yehuda et al, 1990), normal (Kellner et al, 2002) or decreased plasma cortisol (Jensen et al, 1997; Yehuda et al, 1996b), increased lymphocyte glucocorticoid receptors (Yehuda et al, 1991), normal (Kosten et al, 1990) or increased suppression of cortisol in response to dexamethasone (Goenjian et al, 1996; Grossman et al, 1996; Stein et al, 1997; Yehuda et al, 1993), and a buffered ultradian pattern of cortisol release (Yehuda et al, 1996b). Most of these findings are consistent with the hypothesis that PTSD is associated with enhanced negative feedback of the HPA axis, or reduced adrenal output, or a combination of these two mechanisms (for a review, see Yehuda, 2002). The combination of increased hypothalamic CRF activity with normal or low levels of cortisol in PTSD appears to be a unique phenomenon in psychiatric disorders (Kasckow et al, 2001). However, more studies are needed to further characterize hypothalamic CRF activity in PTSD. The sleep EEG response to metyrapone is a measure of the brain response to increases in hypothalamic CRF and thus has potential advantages over other challenge paradigms, such as examining the pituitary response to exogenous CRF. Hence, examining sleep in the context of a metyrapone challenge may provide more information about the brain response to a hypothalamic CRF challenge in PTSD.

Hence, given the remaining uncertainties about the status of delta sleep and hypothalamic CRF in PTSD, and the lack of any study that has examined the relation between the two, we employed a metyrapone challenge to test indirectly if hypothalamic CRF activity is associated with delta sleep in 
PTSD. We report here the effect of metyrapone administration on different domains of sleep disturbances, particularly delta sleep; and endocrine variables, particularly 11deoxycortisol and $\mathrm{ACTH}$, in a sample of male subjects with and without chronic PTSD. We hypothesized that metyrapone would result in a decrease in delta sleep as measured by a period amplitude analysis. Further, we predicted that the metyrapone-induced decrease in delta sleep would be associated with the endocrine (increased 11-deoxycortisol and ACTH) response. Finally, we predicted that PTSD subjects, compared to controls, would have lower levels of delta sleep at baseline and a greater decreases in delta sleep induced by metyrapone.

\section{SUBJECTS AND METHODS}

Medically healthy male subjects were recruited from webbased and newspaper advertisement and from the San Francisco Veterans Affairs Medical Center (SFVAMC) PTSD Outpatient Program. All subjects were given details of the study and asked to sign a written informed consent form if they wished to participate. The study protocol and consent form was approved by the Committee on Human Research at the University of California, San Francisco (UCSF). In all, 24 PTSD subjects and 18 controls completed three nights of polysomnography on the General Clinical Research Center at UCSF. Subjects were included if they met DSM-IV criteria for current PTSD as assessed by the Clinician Administered PTSD Scale (CAPS; Blake et al, 1995). The mean age for the PTSD subjects was $49.4(\mathrm{SD}=5.7)$ and control subjects was $47.8(\mathrm{SD}=9.3)$. The mean CAPS score for the PTSD subjects was $64(\mathrm{SD}=17)$ compared to $2(\mathrm{SD}=4)$ in controls. Only six of the PTSD subjects met current criteria for major depression. All control subjects were negative for lifetime major depression. Subjects were excluded if they met criteria for alcohol or substance abuse within the past 2 years, lifetime criteria for organic mental disorder, schizophrenia, schizoaffective disorder, bipolar disorder, panic disorder, or obsessive compulsive disorder as assessed by the Structured Clinical Interview for DSM-IV (SCID-P; Spitzer et al, 1992). Medical exclusion criteria included any history of brain disease, current systemic illness affecting central nervous system function, or use of any medication affecting the brain. All subjects were free of any psychiatric medications for at least 2 months prior to participation. An oximeter (Respironics Cricket) was used to screen for obstructive sleep apnea (OSA). The cutoff criterion for apnea was 10 desaturation events per hour in bed, which has been shown to have a sensitivity of $98 \%$ and specificity of $48 \%$ in detecting OSA (Sériès et al, 1993). Subjects who screened positive for OSA were excluded. All subjects were alcohol free and restricted to having one optional cup of caffeinated coffee each morning for 2 weeks prior to the three nights of sleep recordings. Ambulatory polysomnography using an Oxford MR95 digital recorder was used to monitor three nights of sleep. Subjects adhered to a stable sleep-wake schedule at their habitual times. Subjects filled out self-report ratings of subjective sleep quality, depression, PTSD symptoms, and mood states utilizing a sleep diary (100 mm visual analog scale), the Beck Depression Inventory (Beck et al, 1961), the Impact of Event Scale-
Revised (Weiss, 1997), and the Profile of Mood States (McNair et al, 1992) each morning after the sleep recordings. The first night of polysomnography was used as an adaptation night and was not utilized in the analyses. On the morning after the second night, blood was collected by venipuncture and plasma was assayed for ACTH, 11deoxycortisol, and cortisol. Subjects received $750 \mathrm{mg}$ of metyrapone every $4 \mathrm{~h}$ for a total of four doses along with $30 \mathrm{~cm}^{3}$ of an antacid. The timing of the doses was adjusted so that the last dose occurred at the subject's self-reported habitual bedtime. The following morning, $8-9.5 \mathrm{~h}$ after the last metyrapone dose, another blood sample was collected to measure ACTH, 11-deoxycortisol, and cortisol. Subjects were all NPO for $9 \mathrm{~h}$ prior to the two morning blood draws.

Objective sleep quality was measured with ambulatory polysomnography (Oxford MR95 recorder). The parameters recorded included an electroencephalogram (EEG) at leads C3 and C4, left and right electro-oculograms (EOG), and submental electromyogram (EMG), and electrocardiogram (EKG) in accordance with standardized guidelines (Rechtschaffen et al, 1968). The EEG and EOG leads were referenced to linked mastoids. All sleep was imported into Pass Plus (Delta Software) analytic software and visually scored in 30-s epochs in accordance to Rechtschaffen and Kales (1968).

Sleep architecture was delineated as the percentage of time spent asleep in NREM stages 1-4 and stage REM. Sleep continuity was measured by calculating sleep maintenance defined as the ratio of total time spent asleep divided by the total recording period between sleep onset and offset. An awakening was defined by EEG arousals lasting $30 \mathrm{~s}$ or longer. REM periods were defined by at least $3 \mathrm{~min}$ of consecutive REM sleep with no less than $30 \mathrm{~min}$ of NREM sleep separating two REM periods. REM measures included: REM percent, REM latency (minutes from sleep onset to first REM period), REM activity (number of rapid eye movements), and REM density (REM activity/minutes REM sleep).

Delta sleep activity was analyzed by period amplitude analysis (PAA) using the Pass Plus (Delta Software) analytic software. Integrated amplitude of $0.3-4.0 \mathrm{~Hz}$ activity per $30 \mathrm{~s}$ epoch was analyzed by NREM/REM cycles across all recorded sleep following the technique described by Feinberg et al $(1987,1991)$ and Travis et al (1991). PAA analyses were conducted on all epochs of NREM and REM sleep. Epochs scored as wake were not included in these analyses. Movement artifact was visually tagged and not included in the analyses.

\section{STATISTICAL ANALYSES}

Descriptive data provide means and standard deviations of the symptom levels and subjective and objective sleep variables pre- and postmetyrapone. The effect of metyrapone on symptom levels, subjective sleep quality visually scored sleep stages, quantitative delta sleep as indexed by period amplitude analysis, and plasma cortisol, ACTH, and 11-deoxycortisol was analyzed by a repeated measures ANOVA with condition (metyrapone administration) as a within-subject factor and group membership as a betweensubject factor. The relations among the changes in delta 
sleep, cortisol, 11-deoxycortisol, and ACTH were analyzed by two-tailed Pearson correlations.

\section{RESULTS}

Metyrapone administration was generally well tolerated in both the PTSD and normal control subjects. The most common side effect was dizziness that occurred in three PTSD and two control subjects. Nausea was reported by two control subjects, both of whom felt relief from the use of an antacid. No subjects dropped out of the study because of adverse effects of metyrapone. The repeated measures ANOVA of subjective sleep quality, the Beck Depression Inventory, Impact of Event Scale-Revised, and the Profile of Mood States showed that metyrapone did not have a significant effect on subjective sleep quality, depression, PTSD symptoms, or mood states when measured the morning after each sleep recording.

The effect of metyrapone on visually scored sleep stages and quantitative delta sleep as indexed by period amplitude analysis is presented in Table 1. PTSD subjects had significantly more stage 1 sleep, and less delta sleep as indexed by stages 3 and 4 , and total delta integrated amplitude. As predicted, metyrapone administration had an arousing effect on the sleep EEG as indexed by a significant increase in awakenings and associated decrease in sleep maintenance. Period amplitude analysis of delta sleep showed a marked decrease in total integrated amplitude, time in the delta band, and number of delta waves as indexed by baseline crossings. There was a significant group by condition effect for total delta integrated amplitude, demonstrating that the effect of metyrapone was significantly greater in controls than PTSD. Finally, by restricting the analysis to delta integrated amplitude to the first three NREM, we found highly significant effects for condition, group, and group-by-condition, suggesting that the impact of metyrapone, as expected, occurs in the first portion of the sleep period.

The effect of metyrapone on AM cortisol, 11-deoxycortisol, and ACTH in PTSD and controls is presented in Table 2. There is a strong effect of metyrapone administration on the 11-deoxycortisol and ACTH response. There is also a marginally significant increase in cortisol postmetyrapone. The next day postmetyrapone cortisol was not suppressed because the samples were obtained in the morning 8-9 h after the last dose of metyrapone. There is a significant effect of PTSD status on the ACTH response, in that PTSD subjects had less of an ACTH rise compared to controls.

The relation among the changes in delta sleep, cortisol, 11-deoxycortisol, and ACTH is presented in a Pearson correlation matrix of change scores in Table 3. In each measure, the change score was calculated as Night 3 (postmetyrapone) minus Night 2 (premetyrapone). The full matrix is presented in order to highlight the relations both within and across the sleep and endocrine measures. The effect of metyrapone on reducing delta-integrated amplitude was significantly associated with the magnitude of increase in both 11-deoxycortisol and ACTH. As expected, changes in visually scored delta sleep were significantly associated with changes in delta-integrated amplitude. However, the only significant association with the endocrine response and changes in visually scored sleep stages was found with stage 3 and 11-deoxycortisol.

\section{DISCUSSION}

Prior to metyrapone administration, we found evidence of decreased delta sleep in PTSD compared to controls, which is similar to the Woodward study (Woodward et al, 2000). We confirmed our prediction that metyrapone would lead to a decrease in delta sleep in both PTSD and controls, although this effect was unexpectedly greater in the control group. Further, we confirmed our prediction that the decrease in delta sleep would be significantly associated with the endocrine (increased 11-deoxycortisol and ACTH) response. This is supportive evidence for the fact that the delta sleep response to metyrapone is a measure of the brain response to a hypothalamic CRF challenge. This model is summarized schematically in Figure 1 . The effect of metyrapone on delta sleep is predicted both by the rise in 11-deoxycortisol, which is most proximal to the adrenal blockade of cortisol synthesis, and by the magnitude of rise in ACTH, which presumably is stimulated by an increase in hypothalamic CRF release secondary to the reduction of feedback regulation by cortisol. These correlations are strong evidence that the effect of metyrapone on sleep is mediated by the response of the HPA axis as opposed to a possible nonendocrine effect of metyrapone. There is also a stronger relation between the ACTH response and deltaintegrated amplitude as opposed to visually scored delta sleep. This is not surprising given that visual sleep stages are insensitive measures of delta sleep. Period amplitude analysis in this study increased our power to detect significant correlations between the delta sleep and endocrine responses to metyrapone.

We were surprised to see a reduced endocrine and delta sleep response in PTSD compared with controls. In the context of possible increased hypothalamic CRF levels in PTSD, the baseline normal cortisol and ACTH levels in our study suggest that the central response of ACTH to CRF is downregulated in PTSD. This would account for a diminished ACTH response to metyrapone in PTSD. However, the lower rise in ACTH levels in PTSD in this study differs from a study of metyrapone administration by Yehuda et al (1996a), who found an increased response. An alternate explanation for the difference in the two studies, as well as our finding of decreased endocrine and sleep responses in PTSD, is that the same dose of metyrapone did not produce the same degree of adrenal suppression of cortisol synthesis. Thus, the reduced endocrine and sleep response to metyrapone in PTSD suggests either that PTSD subjects have downregulated central responses to CRF or that PTSD subjects had less of a CRF response because of less adrenal suppression of cortisol. The latter possibility is supported by the decreased rise in 11-deoxycortisol in PTSD compared to controls.

The endocrine responses to metyrapone in this study do not support a model of reduced adrenal capacity in PTSD as has been suggested by several investigators (Heim et al, 2000; Kanter et al, 2001). Reduced adrenal capacity would be expected to yield a large ratio of ACTH to cortisol release. The mean ACTH/cortisol ratio prior to metyrapone 
Table I Effect of Metyrapone on Visually Scored Sleep and Period Amplitude Analysis of Delta Sleep in PTSD and Controls

\begin{tabular}{|c|c|c|c|c|c|c|c|c|c|c|}
\hline \multirow[b]{3}{*}{ Measures } & \multicolumn{2}{|c|}{ PTSD } & \multicolumn{2}{|c|}{ Controls } & \multirow{2}{*}{\multicolumn{2}{|c|}{ Condition }} & \multirow{2}{*}{\multicolumn{2}{|c|}{ Group }} & \multirow{2}{*}{\multicolumn{2}{|c|}{ Group $\times$ condition }} \\
\hline & \multirow{2}{*}{$\begin{array}{l}\text { Pre-metyrapone } \\
\text { Mean (SD) }\end{array}$} & \multirow{2}{*}{$\begin{array}{c}\text { Post-metyrapone } \\
\text { Mean (SD) }\end{array}$} & \multirow{2}{*}{$\begin{array}{l}\text { Pre-metyrapone } \\
\text { Mean (SD) }\end{array}$} & \multirow{2}{*}{$\begin{array}{c}\text { Post-metyrapone } \\
\text { Mean (SD) }\end{array}$} & & & & & & \\
\hline & & & & & $\mathbf{F}$ & $p$ & $\mathbf{F}$ & $\mathbf{p}$ & $\mathbf{F}$ & $p$ \\
\hline Time in bed (min) & $428.7(67.5)$ & $455.6(65.1)$ & $458.1(76.3)$ & $448.7(98.3)$ & 0.3 & 0.60 & 0.4 & 0.53 & 1.2 & 0.28 \\
\hline Total sleep time & 342.7 (60.4) & $339.8(52.2)$ & $376.5(79.4)$ & 339.1 (52.3) & 2.9 & 0.09 & 1.1 & 0.29 & 2.1 & 0.15 \\
\hline Sleep maintenance & $0.89(0.12)$ & $0.75(0.11)$ & $0.82(0.11)$ & $0.78(0.15)$ & 5.1 & 0.03 & 0.5 & 0.48 & 0.0 & 0.87 \\
\hline WASO $^{\mathrm{a}}$ & $86.0(56.1)$ & | I 5.8 (59.4) & $81.5(52.3)$ & $109.6(102.2)$ & 4.7 & 0.04 & 0.1 & 0.76 & 0.0 & 0.95 \\
\hline Stage I (min) & $28.2(27.4)$ & $23.0(20.9)$ & $13.5(10.9)$ & $18.0(13.2)$ & 0.0 & 0.93 & 4.4 & 0.04 & 1.3 & 0.25 \\
\hline Stage I (\%) & $8.4(8.8)$ & $7.0(6.6)$ & $3.5(2.7)$ & $5.3(3.5)$ & 0.1 & 0.91 & 4.7 & 0.04 & 1.6 & 0.21 \\
\hline Stage 2 (min) & $217.7(57.3)$ & $218.5(51.2)$ & $220.9(67.2)$ & $209.0(39.8)$ & 0.3 & 0.61 & 0.1 & 0.82 & 0.3 & 0.56 \\
\hline Stage 2 (\%) & $63.3(13.5)$ & $64.5(11.8)$ & $59.3(15.1)$ & $61.8(7.6)$ & 0.7 & 0.41 & 1.0 & 0.31 & 0.1 & 0.80 \\
\hline Stage 3 (min) & 13.1 (16.7) & I $5.8(23.6)$ & $32.5(28.3)$ & $26.4(22.3)$ & 0.3 & 0.60 & 5.3 & 0.03 & 1.9 & 0.18 \\
\hline Stage 3 (\%) & $3.7(4.5)$ & $4.4(6.4)$ & $8.6(7.0)$ & $7.9(6.9)$ & 0.0 & 0.99 & 5.5 & 0.02 & 0.8 & 0.39 \\
\hline Stage 4 (min) & $2.9(6.7)$ & $3.3(7.4)$ & $20.4(29.0)$ & $13.0(19.1)$ & 1.1 & 0.30 & 10.3 & 0.00 & 1.4 & 0.24 \\
\hline Stage 4 (\%) & $0.8(1.9)$ & $0.9(2.1)$ & $5.3(7.3)$ & $3.6(5.2)$ & 0.8 & 0.37 & 10.3 & 0.00 & 1.1 & 0.31 \\
\hline Total slow wave & $16.0(21.3)$ & $19.2(26.9)$ & $52.9(46.9)$ & $39.4(38.0)$ & 1.1 & 0.31 & 9.2 & 0.00 & 2.8 & 0.10 \\
\hline Total slow wave (\%) & $4.6(5.9)$ & $5.4(7.4)$ & $14.0(\mid 1.7)$ & II.5 (I0.7) & 0.4 & 0.55 & 9.5 & 0.00 & 1.5 & 0.23 \\
\hline Delta integrated & $129831(36856)$ & $125083(35750)$ & $17|7| 1(52|9|)$ & $141134(39382)$ & 9.6 & 0.00 & 6.5 & 0.01 & 5.2 & 0.03 \\
\hline Amplitude-total & $9727(2126)$ & $9190(1624)$ & $10783(2560)$ & 9459 (2094) & 6.2 & 0.01 & 1.5 & 0.22 & 1.1 & 0.30 \\
\hline Delta time in band & $41035(82 \mid 6)$ & $39|7|(6652)$ & 45531 ( 10836$)$ & 40664 (7765) & 4.9 & 0.03 & 2.0 & 0.16 & 1.0 & 0.33 \\
\hline Delta-integrated amplitude — first three NREM cycles & $110714(32816)$ & $109917(40425)$ & $|4727|(36428)$ & |1 $1739 \mid(32927)$ & 8.0 & 0.01 & 4.6 & 0.04 & 7.2 & 0.01 \\
\hline Stage REM (min) & $77.6(28.2)$ & $77.2(29.9)$ & $84.1(32.0)$ & $69.5(21.0)$ & 3.0 & 0.09 & 0.0 & 0.94 & 2.7 & 0.11 \\
\hline Staghe REM (\%) & $22.8(8.3)$ & $22.6(8.0)$ & $21.9(6.6)$ & $20.6(5.9)$ & 0.7 & 0.33 & 0.4 & 0.51 & 0.3 & 0.59 \\
\hline REM latency & $85(68)$ & $109(98)$ & $106(64)$ & $99(92)$ & 0.3 & 0.61 & 0.1 & 0.79 & 0.8 & 0.37 \\
\hline REM activity & $338(177)$ & 337 (206) & 335 (195) & 307 (I54) & 0.2 & 0.64 & 0.1 & 0.75 & 0.2 & 0.65 \\
\hline REM density & $4.4(1.9)$ & $4.4(2.0)$ & $4.1(2.3)$ & $4.4(2.1)$ & 0.2 & 0.69 & 0.1 & 0.79 & 0.4 & 0.55 \\
\hline
\end{tabular}

${ }^{a}$ WASO: wake after sleep onset (min). 
Table 2 Cortisol, I I-Deoxycortisol, and ACTH Responses to Metyrapone in PTSD and Controls

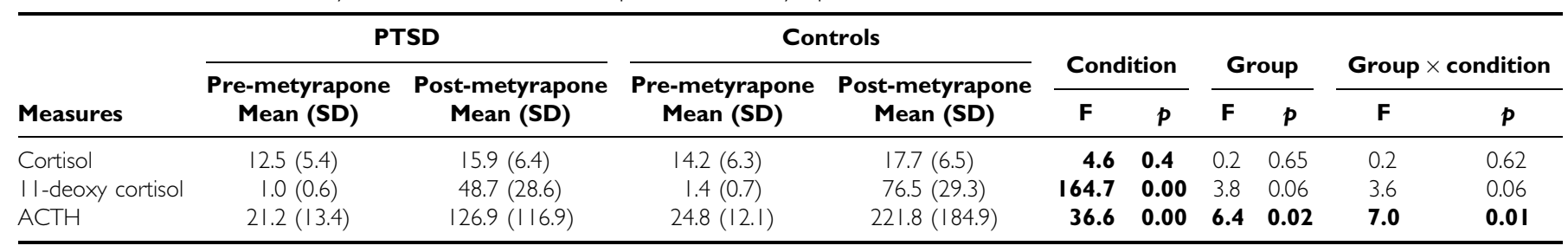

Table 3 : Correlation of Changes in Delta Sleep, Cortisol, II-Deoxycortisol, and ACTH

\begin{tabular}{|c|c|c|c|c|c|c|c|}
\hline & $\begin{array}{c}\Delta \text { Delta IA } r, p \\
\text { (two- tailed) }\end{array}$ & $\Delta$ Stage 3 & $\Delta$ Stage 4 & $\Delta$ Stages 3 and 4 & $\Delta$ Cortisol & $\Delta$ II-Deoxy & $\triangle \mathrm{ACTH}$ \\
\hline$\Delta$ Delta IA & I & & & & & & \\
\hline$\Delta$ Stage 4 & $0.46,0.00 * *$ & $2.16,0.19$ & I & & & & \\
\hline$\Delta$ Stages 3 and 4 & $0.56,0.00 * *$ & $0.77,0.00 * *$ & $0.79,0.00 * *$ & I & & & \\
\hline$\Delta$ Cortisol & $0.16,0.41$ & $-0.01,0.96$ & $-0.23,0.25$ & $-0.16,0.43$ & 1 & & \\
\hline$\Delta \mid$ II-Deoxy & $-0.56,0.00 * *$ & $-0.4 \mid, 0.01 *$ & $-0.01,0.97$ & $-0.29,0.15$ & $-0.28,0.15$ & I & \\
\hline
\end{tabular}

$* p<0.05$.

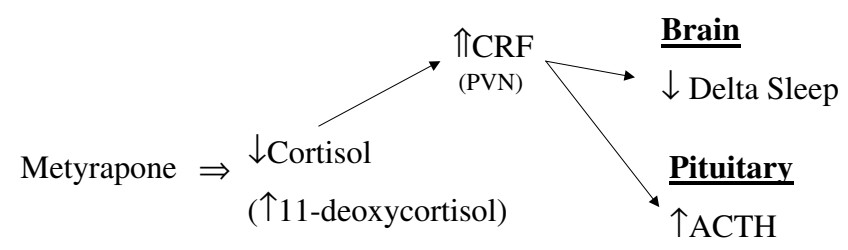

Figure I Model of sleep and endrocrine response to metyrapone. $\mathrm{CRF}=$ Corticotropin-releasing factor, $\mathrm{PVN}=$ paraventricular nucleus, $\mathrm{ACTH}=$ adrenocorticotropic hormone

administration is no different in PTSD $v s$ controls $(\mathrm{PTSD}=1.83$, controls $=1.86 ; t=-0.1, p=0.95)$. The mean $\mathrm{ACTH} /$ cortisol ratio after metyrapone is actually lower, although nonsignificantly, in PTSD compared with controls $(\mathrm{PTSD}=11.20 ;$ controls $=24.31 ; t=-1.4, p=0.16)$, which is evidence against reduced adrenal capacity.

The metyrapone-induced decrease in delta sleep in this study differs from a study of metyrapone and sleep by Gillin et al (1974b), who did not show an activating effect in a small sample $(N=5)$ of young men. It is possible that the relatively young age of the subjects in the Gillin et al study (age 20-25 years) may have had some influence on the results. Both HPA function and sleep are strongly influenced by maturational changes that may explain, for example, why adolescents with major depression do not have similar HPA and sleep abnormalities as depressed adults (Gillin et al, 1981; Rao et al, 1996). This possible age effect is also consistent with the results from Vgontzas et al (2001), who showed that young men did not have an activating response to CRF infusion in contrast to middle age men, who showed a prominent decrease in delta sleep Metyrapone administration in our current study yielded similar results as the Jahn study (Jahn et al, 1996) in that there was a robust decrease in delta sleep.
Our data are consistent with the hypothesis that delta sleep activity is mediated in part by hypothalamic CRF. Delta sleep occurs when CRF is minimally active (Friess et al, 1995). CRF pulses increase after $4-5 \mathrm{~h}$ of sleep and reach peak activity at the beginning of the wake period (Gallagher et al, 1973). Many studies have found an inverse relation between delta sleep and pulsatile cortisol release (see Vgontzas et al, 1999; Born et al, 1991 for a review). Normal aging is associated with a concurrent rise in secretory HPA activity and a reduction in delta sleep (Dodt et al, 1994; Feinberg et al, 1967; Gillin et al, 1981; Van Cauter et al, 1996). Aging is also associated with increased cortisol response and more decreases in delta sleep in response to mild laboratory stressors (Prinz et al, 2000). Several studies in which subjects were forced to sleep in the second half of the night when HPA activity is enhanced have shown that delta sleep emerges only during troughs of cortisol activity (Follenius et al, 1992; Orth et al, 1967; Spath-Schwalbe et al, 1992, 1993; Van Cauter et al, 1991; Weibel et al, 1995; Weitzman et al, 1974, 1983). In the most sophisticated set of studies of peripheral cortisol and delta sleep to date, Gronfier and colleagues calculated secretory rates of cortisol measured every $10 \mathrm{~min}$ using a deconvolutional procedure. Delta sleep activity, as measured by spectral analysis, was inversely correlated with cortisol release and the time delay between delta sleep and cortisol pulses was suggestive of the presence of an unmeasured generator, which they hypothesized to be CRF, in the regulation of these rhythms (Gronfier et al, 1998, 1997). Finally, Vgontzas et al (2001) demonstrated that peripheral CRF infusion in healthy middle-aged men results in a greater decline in delta sleep than in healthy young men. Other studies of CRF infusion in young men have found either a decrease in delta sleep (Holsboer et al, 1988) or no effect on sleep (Born et al, 1989). Exogenous CRF does not cross the blood-brain barrier (Martins et al, 1996) but can 
affect periventricular structures, particularly the hypothalamus. Peripheral administration of $\mathrm{CRH}$ antagonists that do not cross the blood-brain barrier have been found to reduce spontaneous waking (Chang and Opp, 1999). Collectively, these studies are strong evidence that neurohormonal CRF, separate from neurotransmitter CRF, has a role in sleep-wake regulation.

$\mathrm{CRH}$ neurons in the PVN project via the median eminence to the hypothalamo-hypophyseal portal system, which leads to an increase in pituitary ACTH. Theoretically, the decrease in delta sleep could be related to changes in pituitary ACTH or adrenal cortisol release. However, ACTH infusion has been shown to suppress REM but not slowwave sleep, which argues against the primary role of ACTH in decreasing delta (Born et al, 1989; Gillin et al, 1974a). Further, many studies show that cortisol infusion increases delta sleep (Bohlhalter et al, 1997; Born et al, 1991, 1989; Fehm et al, 1986; Hartog, 1964). Thus, the metyrapone effect on delta sleep is not likely to be related to changes in ACTH and cortisol release. One possible mechanism to explain the effect of metyrapone on delta sleep is that the increase in PVN CRF release affects other brain areas involved in sleep or arousal. This possibility is supported by studies that have shown that some PVN CRF neurons project to the locus ceruleus (Aston-Jones et al, 1986; Valentino et al, 1992). For example, Valentino et al (1992) showed that retrograde labeling of CRF terminals in the locus ceruleus originated in the PVN. Support for this mechanism also comes from a study which showed that metyrapone administration results in c-fos induction in the locus ceruleus (Rotllant et al, 2002). CRF projections from the PVN to the locus ceruleus may be a point of integration between neurohormonal and neurotransmitter CRF systems (Valentino et al, 1992). It is possible that stimulation of the locus ceruleus by way of CRF neurons originating in the PVN is of sufficient magnitude to affect a sensitive measure of sleep depth, delta-integrated amplitude, but not of sufficient magnitude to induce anxiety or panic.

In this study, metyrapone caused objective sleep disturbance in the absence of any measurable change in selfreport arousal or anxiety. Interestingly, unmedicated patients with Addison's disease have fragmented sleep, which is reversed with glucocorticoid replacement (GarciaBorreguero et al, 2000). Adrenalectomy leads to increases in CRF activity in the PVN, but decreases in extrahypothalamic areas such as the central nucleus of the amygdala and bed nuclei of the stria terminalis (Watts and Sanchez-Watts, 1995). Patients with Addison's disease who are off glucocorticoids would be expected to have increased CRF activity in the PVN but decreases in extrahypothalamic sites. Hence, Addison's disease is associated with EEG activation but patients are in general not highly symptomatic with anxious arousal. Similarly, metyrapone activates hypothalamic but not extrahypothalamic CRF and the use of this drug is associated with EEG arousal in the absence of increased anxiety. The fact that both neurohormonal and neurotransmitter CRF systems affect sleep and arousal have important implications for understanding insomnia in the context of neuropsychiatric disorders. It is possible for sleep to be disrupted in the absence of anxious arousal states.

In depression, sleep disturbance is highly associated with increased hypothalamic HPA activity (Rush and Weissen- burger, 1994). Multiple studies have found that nonsuppression of cortisol with the dexamethasone suppression test (DST) is associated with reduced delta sleep and short REM latency (Asnis et al, 1983; Giles et al, 1987; Hubain et al, 1998; Kerkhofs et al, 1986; Rush et al, 1982). Many studies have reported on the relation between REM latency and DST nonsuppression (reviewed in Rush et al, 1997) without commenting on delta sleep. Several investigators have commented that short REM latency can arise from a deficit in delta sleep (Feinberg and Koresko, 1965; Giles et al, 1998; Kupfer and Ehlers, 1989). The association between hypercortisolemia and reduced delta sleep, frequently observed in depression (Gold et al, 1988a, b), is consistent with the hypothesis that increased hypothalamic CRF causes a decrease in delta sleep.

The low baseline delta sleep in PTSD is consistent with a model of increased hypothalamic CRF activity in this group. However, decreased delta sleep can have multiple causes independent of CRF. Delta sleep is regulated by a complex interaction between ascending arousal systems, intrinsic sleep promoting brain areas, and GABAergic inhibitory inputs, which allow for reduced arousal and electrical synchrony of cortical neurons (for a review see Jones, 2000). Decreased delta sleep is also found in schizophrenia, depression, normal aging, and brain atrophy (for a review see Neylan et al, 2003). Although, we suggest that decreased baseline delta sleep in PTSD may in part be related to increases in basal levels of both hypothalamic and extrahypothalamic CRF, it is likely that other mechanisms contribute to this finding.

As previously mentioned, there are several alternative interpretations of the data not involving CRF that should be considered. One possibility that explains both the diminished endocrine and sleep response to metyrapone in PTSD was that there were group differences in the pharmacokinetics of metyrapone. For example, if PTSD subjects for any number of reasons had less bioavailability of metyrapone, then the diminished sleep and endocrine response may be related to less CRF release as opposed to downregulation of CRF receptors. Although there were no significant differences in body mass index in our PTSD and control subjects, it is at least theoretically possible that there were group differences in bioavailability of metyrapone. As previously discussed, the endocrine response to metyrapone was assessed by measuring $\mathrm{ACTH}$ and 11 deoxycortisol the morning after metyrapone administration given at habitual sleep onset time. In order to fully understand the effect of the endocrine challenge on delta sleep in PTSD and controls, and address any issues regarding bioavailability of metyrapone, it will be necessary to confirm comparable cortisol suppression across groups by repeated sampling of nocturnal hormone activity during the sleep recordings. In addition, given the known inhibitory effect of CRF on the somatotropic axis (Holsboer et al, 1988; Steiger et al, 1992) and the known relation between delta sleep and growth hormone release (Van Cauter et al, 2000), it will be necessary to measure growth hormone responses in order to understand fully the effect of metyrapone on delta sleep.

In summary, the results from this study demonstrate that metyrapone administration causes an increase in awakenings and marked decrease in quantitative measures of delta sleep, significantly greater in controls compared to PTSD. 
The decline in delta sleep was significantly associated with the magnitude of increase in both 11-deoxycortisol and ACTH. This suggests that the delta sleep response to metyrapone is a measure of the brain response to a hypothalamic CRF challenge. PTSD subjects demonstrated a diminished endocrine and delta sleep response to metyrapone, which suggests either that PTSD had less CRF release induced by metyrapone or are less responsive to $\mathrm{CRF}$.

\section{ACKNOWLEDGEMENTS}

This work was supported by the National Institutes of Health (TCN: MH057157), the General Clinical Research Center, Moffitt Hospital, University of California, San Francisco, with funds provided by the National Center for Research Resources, 5 M01 RR-00079, US Public Health Service, a Veterans Affairs Merit Review grant (Yehuda), and the Sierra Pacific Mental Illness Research, Education, and Clinical Center (MIRECC).

\section{REFERENCES}

Akil HA, Morano MI (1995). Stress. In: Bloom FE, Kupfer DJ (eds) Psychopharmacology: The fourth Generation of Progress. New York: Raven Press. pp 773-785.

Asnis GM, Halbreich U, Sachar EJ, Nathan RS, Ostrow LC, Novacenko $\mathrm{H}$ et al (1983). Plasma cortisol secretion and REM period latency in adult endogenous depression. Am J Psychiatry 140: $750-753$.

Aston-Jones G, Ennis M, Pieribone VA, Nickell WT, Shipley MT (1986). The brain nucleus locus coeruleus: restricted afferent control of a broad efferent network. Science 234: 734-737.

Baker DG, West SA, Nicholson WE, Ekhator NN, Kasckow JW, Hill KK et al (1999). Serial CSF corticotropin-releasing hormone levels and adrenocortical activity in combat veterans with posttraumatic stress disorder. Am J Psychiatry 156: 585-588.

Jones BE (2000). Basic mechanisms of sleep-wake states. In: MH K, T R, WC D (eds) Principles and Practice of Sleep Medicine. 3rd edn. Philadelphia: W.B. Saunders. pp 134-154.

Beck AT, Ward CH, Mendelson M, Mock J, Erbaugh J (1961). An inventory for measuring depression. Arch Gen Psychiatry 4: 561-571.

Blake DD, Weathers FW, Nagy LM, Kaloupek DG, Gusman FD, Charney DS et al (1995). The development of a clinicianadministered PTSD scale. J Traumatic Stress 8: 75-90.

Bohlhalter S, Murck H, Holsboer F, Steiger A (1997). Cortisol enhances non-REM sleep and growth hormone secretion in elderly subjects. Neurobiol Aging 18: 423-429.

Borbely AA, Achermann P (2000). Homeostasis of human sleep and models of sleep regulation. In: Kryger $\mathrm{MH}$, Roth T, Dement WC (eds) Principles and Practice of Sleep Medicine. Philadelphia: W.B. Saunders. pp 377-390.

Born J, DeKloet ER, Wenz H, Kern W, Fehm HL (1991). Gluco- and antimineralocorticoid effects on human sleep: a role of central corticosteroid receptors. Am J Physiol 260: E183-E188.

Born J, Spath-Schwalbe E, Schwakenhofer H, Kern W, Fehm HL (1989). Influences of corticotropin-releasing hormone, adrenocorticotropin, and cortisol on sleep in normal man. J Clin Endocrinol Metab 68: 904-911.

Bremner JD, Licinio J, Darnell A, Krystal JH, Owens MJ, Southwick SM et al (1997). Elevated CSF corticotropin-releasing factor concentrations in posttraumatic stress disorder. Am J Psychiatry 154: 624-629.
Brown TM, Boudewyns PA (1996). Periodic limb movements of sleep in combat veterans with posttraumatic stress disorder. $J$ Traumatic Stress 9: 129-136.

Burade VS, Jain MR, Khan FA, Saha SG, Subhedar N (1996). Involvement of corticosteroid-like neurosteroids in pentobarbital-induced sleep. Neuroreport 8: 139-141.

Chang FC, Opp MR (1998). Blockade of corticotropin-releasing hormone receptors reduces spontaneous waking in the rat. $A m J$ Physiol 275: R793-R802.

Chang FC, Opp MR (1999). Pituitary CRH receptor blockade reduces waking in the rat. Physiol Behav 67: 691-696.

Chang FC, Opp MR (2001). Corticotropin-releasing hormone (CRF) as a regulator of waking. Neurosci Biobehav Rev 25: 445-453.

Dagan Y, Lavie P, Bleich A (1991). Elevated awakening thresholds in sleep stage 3-4 in war-related post-traumatic stress disorder. Biol Psychiatry 30: 618-622.

De Bellis MD, Baum AS, Birmaher B, Keshavan MS, Eccard CH, Boring AM et al (1999). Developmental traumatology Part I: biological stress systems. Biol Psychiatry 45: 1259-1270.

Dodt C, Theine KJ, Uthgenannt D, Born J, Fehm HL (1994). Basal secretory activity of the hypothalamo-pituitary-adrenocortical axis is enhanced in healthy elderly. An assessment during undisturbed night-time sleep. Eur J Endocrinol 131: 443-450.

Dow BM, Kelsoe JR, Jr, Gillin JC (1996). Sleep and dreams in Vietnam PTSD and depression. Biol Psychiatry 39: 42-50.

Ehlers CL, Reed TK, Hendrikson SJ (1986). Effects of corticotropin-releasing factor amd growth hormone-releasing factor on sleep and activity in rats. Neuroendocrinology 42: 467-474.

Fehm HL, Benkowitsch R, Kern W, Fehm-Wolfsdorf G, Pauschinger P, Born J (1986). Influences of corticosteroids, dexamethasone, and hydrocortisone on sleep in humans. Neuropsychobiology 16: 198-204.

Feinberg I (1974). Changes in sleep cycle patterns with age. $J$ Psychiatr Res 10: 283-306.

Feinberg I, Floyd TC, March JD (1987). Effects of sleep loss on delta $(0.3-3 \mathrm{~Hz})$ EEG and eye movement density: new observations and hypotheses. Electroencephalography Clin Neurophysiol 67: 217-221.

Feinberg I, Floyd TC, March JD (1991). Acute deprivation of the terminal 3.5 hours of sleep does not increase delta $(0-3 \mathrm{~Hz})$ electroencephalograms in recovery sleep. Sleep 14: 316-319.

Feinberg I, Koresko RL (1965). Electrophysiological sleep patterns in schizophrenia. Compr Psychiatry 6: 21-24.

Feinberg I, Koresko RL, Heller N (1967). EEG sleep patterns as a function of normal and pathological aging in man. J Psychiatr Res 5: 107-144.

Fiad TM, Kirby JM, Cunningham SK, McKenna TJ (1994). The overnight single-dose metyrapone test is a simple and reliable index of the hypothalamic-pituitary-adrenal axis [see comments]. Clin Endocrinol 40: 603-609.

Follenius M, Brandenburger G, Bandesapt JJ, Libert JP, Ehrhart J (1992). Nocturnal cortisol release in relation to sleep structure. Sleep 15: 21-27.

Friess E, von Bardeleben U, Wiedemann K, Lauer CJ, Holsboer F (1994). Effects of pulsatile cortisol infusion on sleep-EEG and nocturnal growth hormone release in healthy men. J Sleep Res 3: 73-79.

Friess E, Wiedemann K, Steiger A, Holsboer F (1995). The hypothalamic-pituitary-adrenocortical system and sleep in man. Adv Neuroimmunol 5: 111-125.

Gallagher TF, Yoshida K, Roffwarg HD, Fukushima DK, Weitzman ED, Hellman L (1973). ACTH and cortisol secretory patterns in man. J Clin Endocrinol Metab 36: 1058-1068.

Garcia-Borreguero D, Wehr TA, Larrosa O, Granizo JJ, Hardwick $\mathrm{D}$, Chrousos GP et al (2000). Glucocorticoid replacement is permissive for rapid eye movement sleep and sleep consolida- 
tion in patients with adrenal insufficiency. J Clin Endocrinol Metab 85: 4201-4206.

Giles DE, Kupfer DJ, Rush AJ, Roffwarg HP (1998). Controlled comparison of electrophysiological sleep in families of probands with unipolar depression. Am J Psychiatry 155: 192-199.

Giles DE, Schlesser MA, Rush AJ et al (1987). Polysomnographic findings and dexamethasone nonsuppression in unipolar depression: a replication and extention. Biol Psychiatry 22: 872-882.

Gillin JC, Duncan WC, Murphy DL, Post RM, Wehr TA, Goodwin FK et al (1981). Age-related changes in sleep in depressed and normal subjects. Psychiatry Res 4: 73-78.

Gillin JC, Jacobs LS, Snyder F, Henkin RI (1974a). Effects of ACTH on the sleep of normal subjects and patients with Addison's disease. Neuroendocrinology 15: 21-31.

Gillin JC, Jacobs LS, Snyder F, Henkin RI (1974b). Effects of decreased adrenal corticosteroids: changes in sleep in normal subjects and patients with adrenal cortical insufficiency. Electroencephalography Clin Neurophysiol 36: 283-289.

Glaubman H, Mikulincer M, Porat A, Wasserman O (1990). Sleep of chronic post-traumatic patients. J Traumatic Stress 3: 255-263.

Goenjian AK, Yehuda R, Pynoos RS, Steinberg AM, Tashjian M, Yang RK et al (1996). Basal cortisol, dexamethasone suppression of cortisol, and MHPG in adolescents after the 1988 earthquake in Armenia. Am J Psychiatry 153: 929-934.

Gold PW, Goodwin FK, Chrousos GP (1988a). Clinical and biochemical manifestations of depression. Relation to the neurobiology of stress (1). N Engl J Med 319: 348-353.

Gold PW, Goodwin FK, Chrousos GP (1988b). Clinical and biochemical manifestations of depression. Relation to the neurobiology of stress (2). N Engl J Med 319: 413-420.

Gronfier C, Chapotot F, Weibel L, Jouny C, Piquard F, Brandenberger G (1998). Pulsatile cortisol secretion and EEG delta waves are controlled by two independent but synchronized generators. Am J Physiol 275: E94-E100.

Gronfier C, Luthringer R, Follenius M, Schaltenbrand N, Macher JP, Muzet A et al (1997). Temporal relationships between pulsatile cortisol secretion and electroencephalographic activity during sleep in man. Encephalography Clin Neurophysiol 103: 405-408.

Grossman R, Yehuda R, Boisoneau D, Schmeidler J (1996). Prolactin response to low-dose dexamethasone challenge in combat-exposed veterans with and without posttraumatic stress disorder and normal controls. Biol Psychiatry 40: 1100-1105.

Hartog M (1964). Effect of corticosteroids on serum growth hormone. Lancet 2: 376-378.

Hefez A, Metz L, Lavie P (1987). Long-term effects of extreme situational stress on sleep and dreaming. Am J Psychiatry 144: 344-347.

Heim C, Ehlert U, Hellhammer DH (2000). The potential role of hypocortisolism in the pathophysiology of stress-related bodily disorders. Psychoneuroendocrinology 25: 1-35.

Heim C, Newport DJ, Bonsall R, Miller AH, Nemeroff CB (2001). Altered pituitary-adrenal axis responses to provocative challenge tests in adult survivors of childhood abuse. $A m J$ Psychiatry 158: 575-581.

Holsboer F, van Bardeleben U, Steiger A (1988). Effects of intravenous corticotropin-releasing hormone upon sleep-related growth hormone surge and sleep EEG in man. Neuroendocrinology 48: 32-38.

Hubain PP, Staner L, Dramaix M, Kerkhofs M, Papadimitriou G, Mendlewicz J et al (1998). The dexamethasone suppression test and sleep electroencephalogram in nonbipolar major depressed inpatients: a multivariate analysis. Biol Psychiatry 43: 220-229.

Hurwitz TD, Mahowald MW, Kuskowski M, BE E (1998). Polysomnographic sleep is not clinically impaired in Vietnam combat veterans with chronic posttraumatic stress disorder. Biol Psychiatry 44: 1066-1073.
Jahn H, Wiedermann K, Steiger A (1996). Effects of metyrapone treatment upon hormonal secretion and sleep. Eur Neuropsychopharmacol Suppl. 3: 175.

Jensen CF, Keller TW, Peskind ER, McFall ME (1997). Behavioral and neuroendocrine responses to sodium lactate infusion in subjects with posttraumatic stress disorder. Am J Psychiatry 154: 266-268.

Kalin NH, Shelton SE, Barksdale CM, Brownfield MS (1987). A diurnal rhythm in cerebrospinal fluid corticotrophin-releasing hormone different from the rhythm of pituitary-adrenal activity. Brain Res 426: 385-391.

Kanter ED, Wilkinson CW, Radant AD, Petrie EC, Dobie DJ, McFall ME et al (2001). Glucocorticoid feedback sensitivity and adrenocortical responsiveness in posttraumatic stress disorder. Biol Psychiatry 50: 238-245.

Kasckow JW, Baker D, Geracioti Jr TD (2001). Corticotropinreleasing hormone in depression and post-traumatic stress disorder. Peptides 22: 845-851.

Kellner M, Baker DG, Yassouridis A, Bettinger S, Otte C, Naber D et al (2002). Mineralocorticoid receptor function in patients with posttraumatic stress disorder. Am J Psychiatry 159: 1938-1940.

Kerkhofs M, Missa JN, Mendlewicz J (1986). Sleep eletroencephalographic measures in primary major depressive disorder: distinction between DST suppressor and nonsuppressor patients. Biol Psychiatry 21: 225-228.

Klein E, Koren D, Arnon I, Lavie P (2002). No evidence of sleep disturbance in post-traumatic stress disorder: a polysomnographic study in injured victims of traffic accidents. Isr J Psychiatry Relat Sci 39: 3-10.

Kosten TR, Wahby V, Giller EJ, Mason J (1990). The dexamethasone suppression test and thyrotropin-releasing hormone stimulation test in posttraumatic stress disorder. Biol Psychiatry 28: 657-664.

Kramer M, Kinney L (1988). Sleep patterns in trauma victims with disturbed dreaming. Psychiatric J Univ Ottawa 13: 12-16.

Kupfer DJ, Ehlers CL (1989). Two roads to rapid eye movement latency. Arch Gen Psychiatry 46: 945-948.

Lavie P, Hefez A, Halperin G, Enoch D (1979). Long-term effects of traumatic war-related events on sleep. Am J Psychiatry 136: 175-178.

Lemieux AM, Coe CL (1995). Abuse-related posttraumatic stress disorder: evidence for chronic neuroendocrine activation in women. Psychosomatic Med 57: 105-115.

Liberzon I, Abelson JL, Flagel SB, Raz J, Young EA (1999). Neuroendocrine and psychophysiologic responses in PTSD: a symptom provocation study. Neuropsychopharmacology 21: 4050.

Maes M, Lin A, Bonaccorso S, van Hunsel F, Van Gastel A, Delmeire L et al (1998). Increased 24-hour urinary cortisol excretion in patients with post-traumatic stress disorder and patients with major depression, but not in patients with fibromyalgia. Acta Psychiatr Scand 98: 328-335.

Martins JM, Kastin AJ, Banks WA (1996). Unidirectional specific and modulated brain to blood transport of corticotropinreleasing hormone. Neuroendocrinology 63: 338-348.

Mason JW, Giller EL, Kosten TR, Ostroff RB, Podd L (1986). Urinary free-cortisol levels in posttraumatic stress disorder patients. J Nervous Mental Dis 174: 145-149.

McNair DM, Lorr M, Droppleman LF (1992). Profile of Mood States Manual, 1992 ed. Education and Industrial Testing Service: San Diego.

Mellman T, Kumar A, Kulick-Bell R, Kumar M, Nolan B (1995c). Nocturnal/daytime urine noradrenic measures and sleep in combat-related PTSD. Biol Psychiatry 38: 174-179.

Mellman TA, David D, Kulick-Bell R, Hebding J, Nolan B (1995b). Sleep disturbance and its relationship to psychiatric morbidity after Hurricane Andrew. Am J Psychiatry 152: 1659-1663. 
Mellman TA, Kulick-Bell R, Ashlock LE, Nolan B (1995a). Sleep events among veterans with combat-related posttraumatic stress disorder. Am J Psychiatry 152: 110-115.

Mellman TA, Nolan B, Hebding J, Kulick-Bell R, Dominguez R (1997). A polysomnographic comparison of veterans with combat-related PTSD, depressed men, and non-ill controls. Sleep 20: 46-51.

Neylan TC, Reynolds CF, Kupfer DJ (2003). Sleep Disorders, In: Hales RE, Yudofsky SC, Talbott JA (eds) American Psychiatric Publishing Textbook of Clinical Psychiatry, 4th edn American Psychiatric Publishing: Washington DC. pp 975-1000.

Orth DN, Island DP, Liddle GW (1967). Experimental alteration of the circadian rhythm in plasma cortisol (17-OHCS) concentration in man. J Clin Endocrinol Metab 27: 549-555.

Pitman RK, Orr SP (1990). Twenty-four hour urinary cortisol and catecholamine excretion in combat-related posttraumatic stress disorder. Biol Psychiatry 27: 245-247.

Prinz PN, Bailey SL, Woods DL (2000). Sleep impairments in healthy seniors: roles of stress, cortisol, and interleukin-1 beta. Chronobiol Int 17: 391-404.

Rao U, Dahl RE, Ryan ND, Birmaher B, Williamson DE, Giles DE et al (1996). The relationship between longitudinal clinical course and sleep and cortisol changes in adolescent depression. Biol Psychiatry 40: 474-484.

Rasmusson AM, Lipschitz DS, Wang S, Hu S, Vojvoda D, Bremner JD et al (2001). Increased pituitary and adrenal reactivity in premenopausal women with posttraumatic stress disorder. Biol Psychiatry 50: 965-977.

Rechtschaffen A, Kales A, United States. National Institute of Neurological Diseases and Blindness. Neurological Information Network, California. University LABIS (1968). A Manual of Standardized Terminology, Techniques and Scoring System for Sleep Stages of Human Subjects. US Deparment of Health Education and Welfare: Bethesda, MD.

Riemann D, Berger M, Voderholzer U (2001). Sleep and depression - results from psychobiological studies: an overview. Biol Psychol 57: 67-103.

Ross RJ, Ball WA, Dinges DF, Kribbs NB, Morrison AR, Silver SM et al (1994a). Rapid eye movement sleep disturbance in posttraumatic stress disorder. Biol Psychiatry 35: 195-202.

Ross RJ, Ball WA, Dinges DF, Kribbs NB, Morrison AR, Silver SM et al (1994b). Motor dysfunction during sleep in posttraumatic stress disorder. Sleep 17: 723-732.

Roszell DK, McFall ME, Malas KL (1991). Frequency of symptoms and concurrent psychiatric disorder in Vietnam veterans with chronic PTSD. Hospital Commun Psychiatry 42: 293-296.

Rotllant D, Ons S, Carrasco J, Armario A (2002). Evidence that metyrapone can act as a stressor: effect on pituitary-adrenal hormones, plasma glucose and brain c-fos induction. Eur $J$ Neurosci 16: 693-700.

Rush AJ, Giles DE, Roffwarg HP, Parker CR (1982). Sleep EEG and dexamethasone suppression test finding in outpatients with unipolar major depressive disorders. Biol Psychiatry 17: 327-341.

Rush AJ, Giles DE, Schlesser MA, Orsulak PJ, Weissenburger JE, Fulton CL et al (1997). Dexamethasone response, thyrotropinreleasing hormone stimulation, rapid eye movement latency, and subtypes of depression. Biol Psychiatry 41: 915-928.

Rush AJ, Weissenburger JE (1994). Melancholic symptom features and DSM-IV. Am J Psychiatry 151: 489-498.

Sériès F, Marc I, Cormier Y, La Forge J (1993). Utility of nocturnal home oximetry for case finding in patients with suspected sleep apnea hypopnea syndrome [see comments]. Ann Intern Med 119: 449-453.

Smith MA, Davidson J, Ritchie JC, Kudler H, Lipper S, Chappell P et al (1989). The corticotropin-releasing hormone test in patients with posttraumatic stress disorder. Biol Psychiatry 26: 349-355.
Spath-Schwalbe E, Scholler T, Kern W, Fehm HL, Born J (1992). Nocturnal SCTH and corticol secretion depends on sleep duration and decreases in association with spontaneous awakening in the morning. J Clin Endocrinol Metab 75: 1431-1435.

Spath-Schwalbe E, Uthgenannt D, Voget G (1993). Corticotropinreleasing hormone-induced adrenocorticotropin and cortisol secretion depends on sleep and wakefulness. J Clin Endocrinol Metab 75: 1170-1173.

Spitzer RL, Williams JB, Gibbon M, First MB (1992). The structured clinical interview for DSM-III-R (SCID): I. History rationale, and description. Arch Gen Psychiatry 49: 624-629.

Steiger A, Guldner J, Hemmeter U, Rothe B, Wiedemann K, Holsboer F (1992). Effects of growth hormone-releasing hormone and somatostatin on sleep EEG and nocturnal hormone secretion in male controls. Neuroendocrinology 56: 566-573.

Stein MB, Yehuda R, Koverola C, Hanna C (1997). Enhanced dexamethasone suppression of plasma cortisol in adult women traumatized by childhood sexual abuse. Biol Psychiatry 42: 680-686.

Travis F, Maloney T, Means M, March JD, Feinberg I (1991). Acute deprivation of the terminal four hours of sleep does not increase delta $(0-3-\mathrm{Hz})$ electroencephalograms: a replication. Sleep 14: $320-324$.

Uchida S, Feinberg I, March JD, Atsumi Y, Maloney T (1999). A comparison of period amplitude analysis and FFT power spectral analysis of all-night human sleep EEG. Physiol Behav 67: 121-131.

Valentino RJ, Page M, Van Bockstaele E, Aston-Jones G (1992). Corticotropin-releasing factor innervation of the locus coeruleus region: distribution of fibers and sources of input. Neuroscience 48: 689-705.

Van Cauter E, Blackman JD, Roland D, Spire JP, Refetoff S, Polonsky KS (1991). Modulation of glucose regulation and insulin secretion by circadian rhythmicity and sleep. J Clin Invest 88: 934-942.

Van Cauter E, Leproult R, Kupfer DJ (1996). Effects of gender and age on the levels and circadian rhythmicity of plasma cortisol. $J$ Clin Endocrinol Metab 81: 2468-2473.

Van Cauter E, Leproult R, Plat L (2000). Age-related changes in slow wave sleep and REM sleep and relationship with growth hormone and cortisol levels in healthy men. JAMA 284: 861-868.

Vgontzas AN, Bixler EO, Wittman AM, Zachman K, Lin HM, VelaBueno A et al (2001). Middle-aged men show higher sensitivity of sleep to the arousing effects of corticotropin-releasing hormone than young men: clinical implications. J Clin Endocrinol Metab 86: 1489-1495.

Vgontzas AN, Mastorakos G, Bixler EO, Kales A, Gold PW, Chrousos GP (1999). Sleep deprivation effects on the activity of the hypothalamic-pituitary-adrenal and growth axes: potential clinical implications. Clin Endocrinol 51: 205-215.

Vythilingam M, Anderson GM, Owens MJ, Halaszynski TM, Bremner JD, Carpenter LL et al (2000). Cerebrospinal fluid corticotropin-releasing hormone in healthy humans: effects of yohimbine and naloxone. J Clin Endocrinol Metab 85: 41384145 .

Watts AG, Sanchez-Watts G (1995). Region-specific regulation of neuropeptide mRNAs in rat limbic forebrain neurones by aldosterone and corticosterone. J Physiol 484: 721-736.

Weibel L, Follenius M, Spiegel K, Ehrhart J, Brandenburger G (1995). Comparative effect of night and daytime sleep on the 24hour cortisol secretory profile. Sleep 18: 549-556.

Weiss DS (1997). Structured clinical interview techniques. In: Wilson JP, Keane TM (eds) Assessing Psychological Trauma and PTSD: A Practitioner's Handbook. Guilford Press: New York. pp 493-511. 
Weitzman ED, Nogeire C, Perlow M (1974). Effects of a prolonged 3-hour sleep-wake cycle on sleep stages, plasma cortisol, growth hormone and body temperature in man. J Clin Endocrinol Metab 38: $1018-1030$.

Weitzman ED, Zimmerman JC, Czeisler CA, Ronda J (1983). Cortisol secretion is inhibited during sleep in normal man. J Clin Endocrinol Metab 56: 352-358.

Woodward S, Bliwise D, Friedman M, Gusman F (1996a). Subjective $v s$ objective sleep in Vietnam combat veterans hospitalized for PTSD. J Traumatic Stress 9: 137-143.

Woodward S, Friedman M, Bliwise D (1996b). Sleep and depression in combat-related PTSD. Biol Psychiatry 39: 182-192.

Woodward SH, Bliwise DL, Friedman MJ, Gusman FD (1996c). First night effects in post-traumatic stress disorder inpatients. Sleep 19: 312-317.

Woodward SH, Murburg MM, Bliwise DL (2000). PTSD-related hyperarousal assessed during sleep. Physiol Behav 70: 197-203.

Yehuda R (2002). Current status of cortisol findings in posttraumatic stress disorder. Psychiatr Clin North Am 25: 341-368.

Yehuda R, Kahana B, Binder-Brynes K, Southwick SM, Mason JW, Giller EL (1995). Low urinary cortisol excretion in holocaust survivors with posttraumatic stress disorder. Am J Psychiatry 152: 982-986.

Yehuda R, Levengood RA, Schmeidler J, Wilson S, Guo LS, Gerber D (1996a). Increased pituitary activation following metyrapone administration in post-traumatic stress disorder. Psychoneuroendocrinology 21: 1-16.

Yehuda R, Lowy MT, Southwick SM, Shaffer D, Giller EL (1991). Lymphocyte glucocorticoid receptor number in posttraumatic stress disorder. Am J Psychiatry 148: 499-504.

Yehuda R, Southwick SM, Krystal JH, Bremner D, Charney DS, Mason JW (1993). Enhanced suppression of cortisol following dexamethasone administration in posttraumatic stress disorder. Am J Psychiatry 150: 83-86.

Yehuda R, Southwick SM, Nussbaum G, Wahby V, Giller EL, Mason JW (1990). Low urinary cortisol excretion in patients with posttraumatic stress disorder. J Nervous Mental Dis 178: 366-369.

Yehuda R, Teicher MH, Trestman RL, Levengood RA, Siever LJ (1996b). Cortisol regulation in posttraumatic stress disorder and major depression: a chronobiological analysis. Biol Psychiatry 40: 79-88. 